\title{
Packaging of Bread in Paper Made From Edible Red Algae and Coated with Antimicrobials Retards Microbial Growth in Bread during Storage \\ - Research Note -
}

\author{
Kyoung-Ju Ku', Yun-Hee Hong ${ }^{1}$, Yung Bum Seo ${ }^{2}$, and Kyung Bin Song ${ }^{1 \dagger}$ \\ ${ }^{1}$ Department of Food Science \& Technology, and ${ }^{2}$ Department of Forest Products, \\ Chungnam National University, Daejeon 305-764, Korea
}

\begin{abstract}
To utilize edible red algae paper for food packaging, red algae paper coated with green tea extract or catechin was prepared and microbial growth in bread wrapped with the paper was detemined during storage. The paper coated with green tea extract or catechin had antimicrobial activity against Escherichia coli. Packaging of bread with the red algae paper coated with green tea extract or catechin decreased the populations of total aerobic bacteria and yeast and mold after 2 days of storage by 0.41 and $0.63 \mathrm{log}$ CFU/g, respectively, compared to the control. These results suggest that bread can be packaged by edible red algae paper coated with green tea extract or catechin, resulting in inhibit microbial growth during storage.
\end{abstract}

Key words: antimicrobials, bread, red algae paper, shelf life

\section{INTRODUCTION}

Bread and other bakery products are part of a balanced diet (1), but unpreserved bread is easily susceptible to microbial spoilage. In particular, spore forming bacteria can grow to levels of public health concern (2), although vegetative pathogenic microorganisms should be inactivated during baking. Thus, microbial spoilage is the major problem causing deterioration of bread products during storage (2).

Edible films containing nisin or chitosan as functional materials in the formulation $(3,4)$ are used as a packaging. In addition, for coating of edible films, green tea extract or catechin can be used as anti-oxidative as well as antimicrobial material to extend shelf life of food products (5).

Recently, the use of red algae pulp has been investigated for manufacturing papers (6), and its application in food industry is considered because it is edible. Therefore, the objectives of this study were to prepare edible red algae paper coated with antimicrobials for food packaging, and to determine the microbial growth in bread packaged with the paper during storage.

\section{MATERIALS AND METHODS}

\section{Materials}

Red algae paper was supplied by Pegasus International Co. (Daejeon, Korea). Green tea extract powder was purchased from Dongsuh Co. (Siheung, Korea), and catechin was purchased from Sigma-Aldrich Chemical Co.
(St. Louis, MO, USA). White bread (butter added) was purchased from a local market in Daejeon, Korea.

Coating of red algae paper with antimicrobials

Red algae paper was coated with green tea extract $(1.42 \%, 2.83 \%$, and $5.6 \%, \mathrm{w} / \mathrm{w})$ or catechin $(50,100$, and $200 \mathrm{mg} / 100 \mathrm{~mL}$ ) solution by spraying, and drying at $120^{\circ} \mathrm{C}$ for $1 \mathrm{~min}$.

Antimicrobial activity of red algae paper coated with antimicrobials

Antimicrobial activity of the red algae paper coated with green tea extract or catechin was determined according to a modified method of Ko et al. (7). Listeria monocytogenes and Escherichia coli were cultured in Tryptic Soy Broth and Luria-Bertani broth (Difco Co., Detroit, MI, USA) at $37^{\circ} \mathrm{C}$, respectively, until they reach $10^{9} \mathrm{CFU} / \mathrm{mL}$. The coated red algae paper was cut into $10 \mathrm{~cm} \times 10 \mathrm{~cm}$ squares, treated with UV for $3 \mathrm{hr}$, and then $40 \mu \mathrm{L}$ of the bacterial suspension was placed onto the paper. The paper was then incubated at room temperature for $1 \mathrm{hr}$. After incubation, the paper was placed in $26.95 \mathrm{~mL}$ of $0.1 \%$ peptone water, and homogenized for $3 \mathrm{~min}$. The solution was then diluted with $0.1 \%$ peptone water and the populations of L. monocytogenes and E. coli were counted. All plates were incubated at $37^{\circ} \mathrm{C}$ for $24 \mathrm{hr}$. Each microbial count was the mean of three determinations and was expressed as colony forming units $(\mathrm{CFU} / \mathrm{g})$. 


\section{Packaging of bread with red algae paper}

Bread was wrapped with the red algae papers coated with green tea extract or catechin. The control was bread in a plain paper box supplied by a manufacturer. Bread was stored at room temperature for $72 \mathrm{hr}$.

\section{Microbiological analysis of bread during storage}

Five grams of bread samples was removed using a sterile scalpel, and placed in $45 \mathrm{~mL}$ of $0.1 \%$ peptone water. Samples were then homogenized in a sterile stomacher bag using a Stomacher (MIX 2, AES Laboratoire, France) for $3 \mathrm{~min}$, filtered through a sterile cheese cloth, and diluted with peptone water for microbial counting. Serial dilutions were performed in triplicate on each selective agar plate. Total bacterial counts were determined by plating appropriately diluted samples onto plate count agar (PCA, Difco Co., Detroit, MI, USA). Yeast and mold were plated on plate dextrose agar (PDA, Difco Co., Detroit, MI, USA). Both plates were incubated at $37^{\circ} \mathrm{C}$ for $48 \mathrm{hr}$ and $72 \mathrm{hr}$, respectively. Each microbial count was the mean of three determinations, and was expressed as $\log \mathrm{CFU} / \mathrm{g}$.

\section{Statistical analysis}

Differences were analyzed by Duncan's multiple range tests and analysis of variance using a SAS program (1999, SAS Institute, Inc., Cary, NC, USA).

\section{RESULTS AND DISCUSSION}

Antimicrobial activity of the red algae paper coated with green tea extract or catechin against Escherichia coli is shown in Fig. 1. Increasing concentration of green tea extract or catechin increased inhibition of bacterial growth, resulting in a decrease by 0.9 and $0.8 \log \mathrm{CFU} / \mathrm{g}$ at $5.6 \%$ and $200 \mathrm{mg}$, respectively, compared to the control (Fig. 1). The major component of green tea extract is catechin, which is known to have antioxidant and antibacterial activity (8). Sung (9) reported that addition of $1 \%$ green tea extract reduced populations of Salmonella Typhimurium by $0.9 \log \mathrm{CFU} / \mathrm{g}$ within $24 \mathrm{hr}$. Our results are comparable with the result.

Microbial growth in the bread packaged with the red algae paper was determined during storage. Fig. 2 shows the results of total aerobic bacteria and yeast and mold counts in bread during storage. After two days of storage, populations of total aerobic bacteria in the bread wrapped with the red algae paper coated with catechin or green tea extract were significantly reduced by 0.41 and $0.63 \log \mathrm{CFU} / \mathrm{g}$ (Fig. 2A), respectively, compared to the control. This is mainly due to the antimicrobial activity of catechin in the paper. Fig 2B shows the change in the populations of yeast and mold in bread
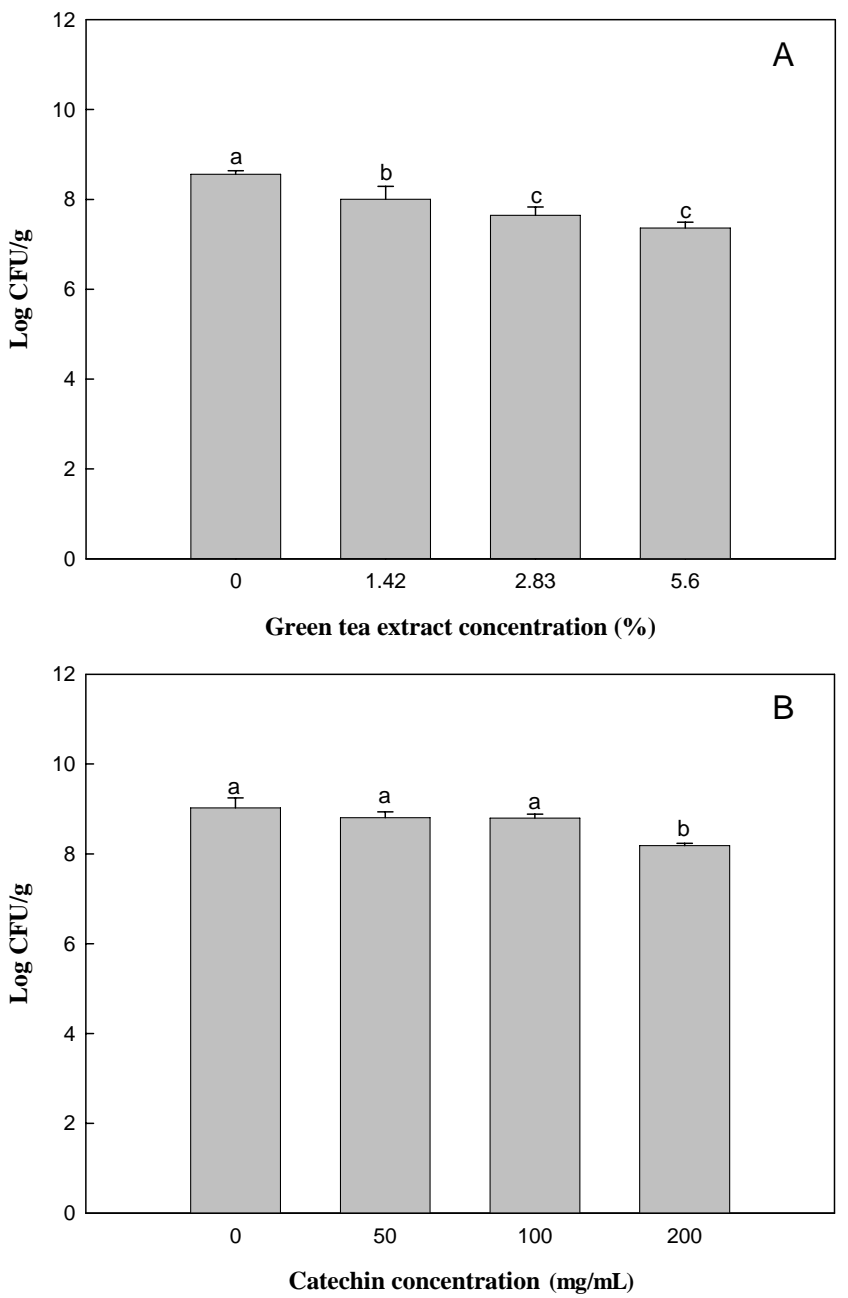

Fig. 1. Antimicrobial activity of red algae paper coated with green tea extract (A) or catechin (B) against Escherichia coli. Bars represent standard error. ${ }^{\mathrm{a}-\mathrm{c}}$ Any means with different letters are significantly different $(\mathrm{p}<0.05)$.

during storage. Like total aerobic bacteria, populations of yeast and mold in bread during storage were also reduced by packaging with the red algae paper coated with catechin or green tea extract. After 1 day of storage, the control reached $4.3 \log \mathrm{CFU} / \mathrm{g}$, while packaging with the red algae paper coated with green tea extract had $3.78 \log \mathrm{CFU} / \mathrm{g}$. In addition, after 2 days of storage, packaging with the red algae paper coated with catechin decreased the populations of yeast and mold by $0.73 \mathrm{log}$ CFU/g more, compared to the control. Kim (10) reported that populations of total aerobic bacteria and yeast and mold in bread wrapped with poly 3-hydroxybutyric acid (PHB) coated with chitosan were reduced by 1 and 2.2 $\log$ CFU/g, respectively, after 3 days of storage. Their results exhibited a similar pattern as the data in this study, although different edible packaging materials were used.

In summary, edible red algae paper coated with green 

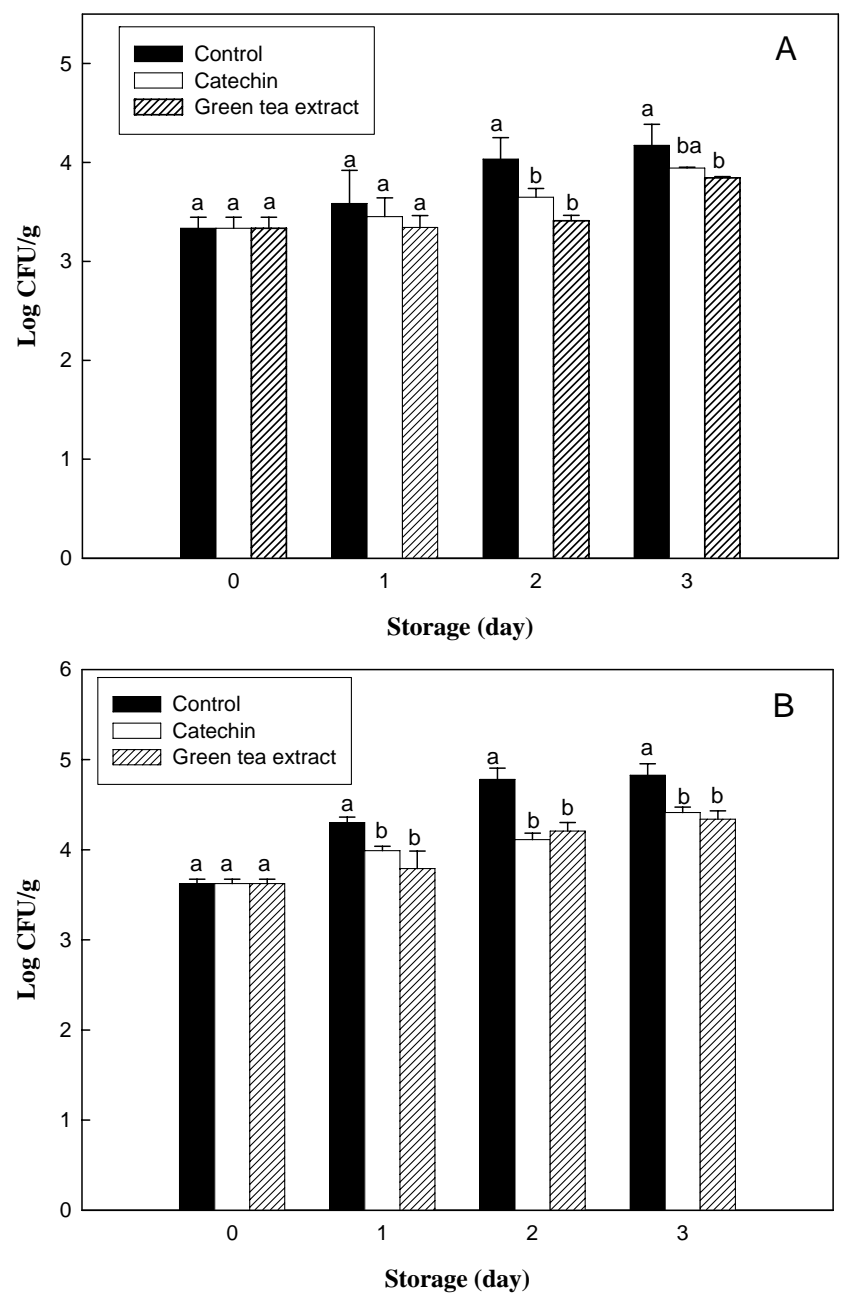

Fig. 2. Changes in populations of total aerobic bacteria (A) and yeast and mold (B) in bread during storage. Bars represent standard error. ${ }^{\mathrm{a}-\mathrm{c}}$ Any means with different letters are significantly different $(\mathrm{p}<0.05)$.

tea extract or catechin as a package for bread was prepared, and the results suggest that bread can be packaged with the paper coated with catechin or green tea extract, resulting in retardation of microbial growth in the bread during storage.

\section{REFERENCES}

1. Smith JP, Daifas DP, El-khoury W, Austia JW. 2002. Microbial safety of bakery products. In Microbial safety of minimally processed foods. Novak JS, Sapers GM, Juneja VK, eds. CRC Press, New York. p 3-34.

2. Needham R, Williams J, Bealesb N, Voysey P, Magana N. 2005. Early detection and differentiation of spoilage of bakery products. Sensors Actuators 106: 20-23.

3. Sanjurjo K, Flores S, Gerschenson L, Jagus R. 2006. Study of the performance of nisin supported in edible films. Food Res Int 39: 749-754.

4. Dhanikula AB, Panchagnulal R. 2004. Development and characterization of biodegradable chitosan films for local delivery of paclitaxel. Am Assoc Pharm Sci J 6: Article 27.

5. Lee SH, Lee MS, Park SK, Bae DH, Ha SD, Song KB. 2004. Physical properties of protein films containing green tea extract and its antioxidant effect on fish paste products. J Korean Soc Food Sci Nutr 33: 1063-1067.

6. Yu HC, Park JH, Seo YB. 2005. Pulp and paper made from Rhodophyta and manufacturing method. Korean Patent 10-2005-0096041.

7. Ko S, Janes ME, Hettiarachchy NS, Johnson MG. 2001. Physical and chemical properties of edible films containing nisin and their action against Listeria monocytogenes. J Food Sci 66: 1006-1011.

8. Bais HP, Walker TS, Stermitz FR, Hufbauer RA, Vivanco JM. 2002. Enantiomeric-dependent phytotoxic and antimicrobial activity of catechin. Plant Physiol 128: 11731179.

9. Sung KC. 2006. A study on the pharmaceutical characteristics and analysis of green tea extract. $J$ Korean Oil Chem Soc 23: 115-124.

10. Kim MR. 2005. Antimicrobial activity of $\mathrm{PHB} /$ chitosan films and quality of white bread packaged with the films. J Korean Living Sci Assoc 14: 321-330.

(Received March 3, 2008; Accepted March 14, 2008) 